LAWRENCE LIVERMORE NATIONAL LABORATORY

\title{
Mars Ascent Propulsion Trades with Trajectory Analysis
}

John C. Whitehead

\section{July 11, 2004}

$40^{\text {th }}$ AIAA/ASME/SAE/ASEE

Joint Propulsion Conference and Exhibit Fort Lauderdale, FL

Paper Number AIAA-2004-4069

AIAA = American Institute of Aeronautics and Astronautics ASME = American Society of Mechanical Engineers SAE = Society of Automotive Engineers ASEE = American Society of Engineering Education 
This document was prepared as an account of work sponsored by an agency of the United States Government. Neither the United States Government nor the University of California nor any of their employees, makes any warranty, express or implied, or assumes any legal liability or responsibility for the accuracy, completeness, or usefulness of any information, apparatus, product, or process disclosed, or represents that its use would not infringe privately owned rights. Reference herein to any specific commercial product, process, or service by trade name, trademark, manufacturer, or otherwise, does not necessarily constitute or imply its endorsement, recommendation, or favoring by the United States Government or the University of California. The views and opinions of authors expressed herein do not necessarily state or reflect those of the United States Government or the University of California, and shall not be used for advertising or product endorsement purposes. 


\title{
Mars Ascent Propulsion Trades with Trajectory Analysis
}

\author{
John C. Whitehead* \\ Lawrence Livermore National Laboratory, Livermore, CA 94551
}

\begin{abstract}
Optimized trajectories to a $500 \mathrm{~km}$ circular orbit are calculated for vehicles having a 100 kg Mars launch mass. Staging trades, thrust optimization, and the importance of vehicle shape for drag are all taken into consideration. The high acceleration of solid rockets requires a steep trajectory for drag avoidance, followed by a relatively large circularization burn, appropriate for a second stage. Liquid thrust reduces drag, resulting in less steep trajectories which have small circularization burns. Liquid propulsion requires less total $\Delta v$, and offers options for multiple stages or just one. Graphs of payload mass versus stage propellant fractions are compared for liquid and solid propulsion.
\end{abstract}

\section{Introduction}

A NASA-funded study by the National Research Council in 2003 placed a high priority on multiple Mars sample return (MSR) missions. ${ }^{1}$ More recently in 2004, the case for MSR has been strengthened by the exciting geology results from JPL's Mars Exploration Rovers. However, a MSR mission has not been planned in detail, due to the high cost and incomplete technology readiness. One missing ingredient is a Mars ascent vehicle (MAV).

Mission costs are on the order of $\$ 1 \mathrm{M} / \mathrm{kg}$ for payloads landed on Mars, typically just hundreds of $\mathrm{kg}$. A MAV in the 100-kg range would save hundreds of millions of dollars per MSR mission attempt, compared to MAV designs that approach or exceed $500 \mathrm{~kg}$. A MAV must deliver $4 \mathrm{~km} / \mathrm{s} \Delta \mathrm{v}$ in minutes, with guidance and control to reach orbit. No rocket system ever built near the size of interest has had such high performance.

Various potential MAV designs have been studied, with consideration of both liquid and solid propellants. ${ }^{2-7}$ The author has suggested miniaturization of pump-fed liquid rocket technology to achieve high propellant fractions ${ }^{8-10}$ Individual studies have included trajectory analysis. ${ }^{11}$ The present paper is intended to more broadly address the significance of trajectory considerations for propulsion choices.

Smaller vehicles have more area per unit mass, so drag is significant even in Mars' thin atmosphere. Solid rockets reach high speeds sooner than liquids, so drag affects trajectory optimization differently for each propulsion choice. This paper presents the results of trajectory calculations using either solid or liquid propellants, focusing on a $100 \mathrm{~kg} \mathrm{MAV}$. Further analysis is done to address specific questions related to staging, vehicle shape, and thrust optimization. Conclusions drawn from this work can be used to guide MAV technology development.

\section{Fundamentals of Reaching Orbit}

Figure 1 depicts two paths to orbit, labeled A and B. Each consists of two propulsive maneuvers, numbered 1 and 2. Path A has a horizontal launch directly into an elliptical orbit, which is circularized. After a vertical launch, the Path B vehicle coasts to a stop at the desired altitude, then it executes a very large circularization burn. Both paths are extreme cases that are never used, but they offer insight because all real trajectories are somewhere in between.

If there is no atmosphere and no hills to hit, the least total $\Delta \mathrm{v}$ to orbit is obtained by following Path $\mathrm{A}$ using infinite thrust. In reality, finite acceleration requires some initial vertical velocity to avoid the terrain. Vacuum conditions may favor solids over liquids, because solids can more closely follow path A due to their higher acceleration. However, avoiding excess drag in an atmosphere requires a substantial initial vertical component, to gain altitude early. Very dense atmospheres tend to favor Path B. Drag avoidance may also favor liquids, since more altitude can be gained at lower speeds than with solids. Detailed calculations are needed to assess a particular situation.

\footnotetext{
* PO Box 808, Mail Stop L-413, AIAA Senior Member.
} 
The historical literature includes trajectory analysis for Mars ascent, even before the density of Mars' atmosphere was known. ${ }^{12}$ Subsequently, the Viking missions to Mars provided the first direct atmospheric measurements in $1976 .{ }^{13}$ A simple exponential decay curve of density with altitude was fit to the data and used herein. Table 1 shows the density assumption along with other fixed constants used to represent Mars. Velocities calculated directly from Table 1 parameters are shown in Table 2.

Table 1. Fixed parameters for Mars calculations.

\begin{tabular}{|l|l|}
\hline Parameter & Value \\
\hline \hline Gravitational constant & $6.67 \mathrm{E}-11 \mathrm{~N}-\mathrm{m}^{2} / \mathrm{kg}^{2}$ \\
\hline Mars mass & $6.42 \mathrm{E} 23 \mathrm{~kg}$ \\
\hline Mars radius & $3.38 \mathrm{E} 6 \mathrm{~m}$ \\
\hline Atmospheric density at surface & $1.7 \mathrm{E}-2 \mathrm{~kg} / \mathrm{m}^{3}$ \\
\hline Atmosphere scale height (1/e decay) & $8.3 \mathrm{E} 3 \mathrm{~m}$ \\
\hline Speed of sound & $2.5 \mathrm{E} 2 \mathrm{~m} / \mathrm{s}$ \\
\hline
\end{tabular}

Table 2. Velocities from physical constants.

\begin{tabular}{|l|l|}
\hline Calculated velocity for Mars & Value \\
\hline \hline Orbital velocity at zero altitude & $3559 \mathrm{~m} / \mathrm{s}$ \\
\hline Orbital velocity at $500 \mathrm{~km}$ altitude & $3322 \mathrm{~m} / \mathrm{s}$ \\
\hline Path A $\Delta v$ to $500 \mathrm{~km}$ Mars orbit (vacuum) & $3796 \mathrm{~m} / \mathrm{s}$ \\
\hline Burn A1 $\Delta v$ & $3679 \mathrm{~m} / \mathrm{s}$ \\
\hline Burn A2 $\Delta v$ & $116 \mathrm{~m} / \mathrm{s}$ \\
\hline Path B $\Delta v$ to $500 \mathrm{~km}$ Mars orbit (vacuum) & $5128 \mathrm{~m} / \mathrm{s}$ \\
\hline Burn B1 $\Delta v$ & $1807 \mathrm{~m} / \mathrm{s}$ \\
\hline Burn B2 $\Delta v$ & $3322 \mathrm{~m} / \mathrm{s}$ \\
\hline
\end{tabular}

In the time-domain simulations, the piecewise linear function graphed in Figure 3 was used to set the drag coefficient. This approximates an idealized curve corresponding to the projectile shape shown as an inset. Table 3 provides baseline simulation parameters that represent vehicle design items. The high thrust listed for the solid rocket option is typical of motors having propellant loads in the range $60-80 \mathrm{~kg}$.

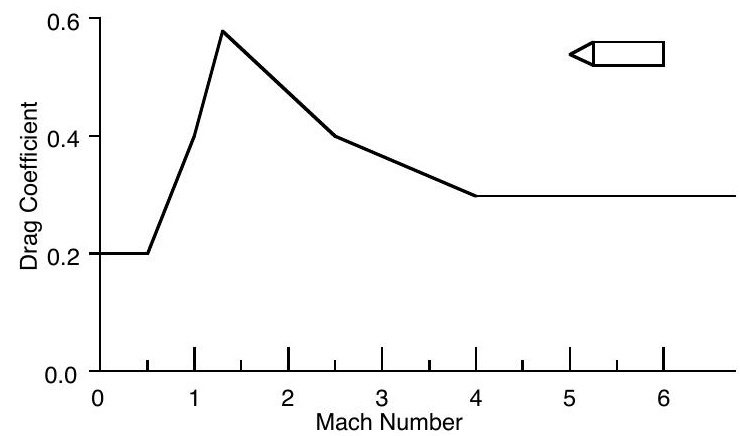

Figure 3. Drag coefficient variation.
Table 3. Vehicle and propulsion initial assumptions.

\begin{tabular}{|l|l|}
\hline Quantity & Value \\
\hline \hline Frontal area (reference for drag) & $0.2 \mathrm{~m}^{2}$ \\
\hline Low speed drag coefficient & $0.2 \quad$ (see graph) \\
\hline Total mass at launch & $100 \mathrm{~kg}$ \\
\hline Solid specific impulse & $280 \mathrm{~s}$ \\
\hline Solid thrust & $10,000 \mathrm{~N}$ \\
\hline Liquid specific impulse & $310 \mathrm{~S}$ \\
\hline Liquid thrust & $1000 \mathrm{~N}$ \\
\hline
\end{tabular}

A 100-kg MAV with a 4:1 aspect ratio would have a diameter of about $0.4 \mathrm{~m}$ (16 inches). Actual drag is increased by non-idealities in vehicle shape and surface texture, as well as by off-axis flow. Therefore, the frontal area used in the simulations is based on a larger $0.5 \mathrm{~m}$ diameter. While solid propellant is denser than liquid, the higher thrust associated with solid motors requires nozzles larger than liquid engines. In the absence of detailed designs, it was assumed that the propellant choice would not affect the MAV volume or shape.

\section{Coding, Testing, and Running the Model}

Simulations were performed using approximately 150 lines of self-contained FORTRAN (numerical integration included). Launches were conducted from the positive $\mathrm{x}$-axis at $\mathrm{x}=\mathrm{r}$, and all motion was confined to the $\mathrm{x}-\mathrm{y}$ plane. Initial velocities were zero for launch (non-rotating planet). A perfect planet was assumed, i.e. inverse-square gravity was directed toward the origin (planet center). The piecewise linear function for the drag coefficient was coded with conditional statements.

Troubleshooting the model was accomplished by trying initial conditions corresponding to circular orbits, with no atmosphere. The integrated position variables, and their rates, required double precision calculations to obtain an accurate orbit circle. Such simple situations, using the numerical model, yielded results in close agreement with the analytical calculations.

After the atmosphere was turned on, additional circular orbit simulations yielded orbital lifetime predictions as a function of altitude, based on a 10-kg empty mass. While the drag equation used was not accurate for rarified flow, 
it is interesting to note that a $100 \mathrm{~km}$ orbit lasted just over half way around, and raising the altitude to $120 \mathrm{~km}$ permitted almost 2.5 orbits before entry.

Launches were subsequently simulated, by choosing a propellant quantity for the primary maneuver, then adjusting the launch angle precisely to obtain a peak altitude of $500 \mathrm{~km}$ within $50 \mathrm{~m}$. The thrust vector was held at the launch angle for 1 second, then aligned with the velocity vector thereafter to avoid steering losses and extra drag. The exact launch angles are meaningful only for the purpose of obtaining efficient simulated trajectories. While a more realistic simulation might model active guidance, the optimizations done are at least sufficient for the intended purpose of comparing different MAV design options.

Circularization was assumed to be loss-less since it occurs in vacuum when acceleration is not critical. Therefore, only the initial burns and resulting coast trajectories to peak altitudes were simulated. A conditional statement stopped each run when the apoapsis was reached. Delivered $\Delta \mathrm{v}$ for each primary ascent burn was calculated from the propellant quantity. Circularization $\Delta \mathrm{v}$ was determined by subtracting the apoapsis velocity from orbital velocity at $500 \mathrm{~km}$. It was thus straightforward to determine the total delivered $\Delta \mathrm{v}$ required for each attempted path to orbit. Given vehicle design data from Table 3, the propellant mass of the primary burn was varied in order to find the least total $\Delta \mathrm{v}$ to orbit.

\section{Trajectory Results}

Results from simulation runs, using Table 3 values, are listed in Table 4. Each case represents the least $\Delta \mathrm{v}$ that was obtained using the methods outlined above to reach a 500-km circular orbit above Mars. Note that the solid rocket ascent in vacuum is almost identical to the ideal Path A to orbit, due to high thrust. The liquid ascent in vacuum has a significant gravity loss, since thrust is only about 2.7 times the Mars launch weight $(100 \mathrm{~kg} \times 3.75$ $\mathrm{m} / \mathrm{s}^{2}$ gravity).

Table 4. Simulation results for baseline MAV designs.

\begin{tabular}{|l|l|l|l|l|}
\hline Ascent option & Init. $\Delta \mathrm{v}$ & Circ. $\Delta \mathrm{v}$ & Total $\Delta \mathrm{v}$ & $\Delta \mathrm{v} / \Delta \mathrm{v}_{\mathrm{A}}$ \\
\hline \hline Solid in vacuum & 3681 & 118 & 3799 & 1.001 \\
\hline Liquid in vacuum & 3856 & 111 & 3967 & 1.045 \\
\hline Solid in atmosphere & 2803 & 1567 & 4371 & 1.151 \\
\hline Liquid in atmosphere & 3900 & 257 & 4157 & 1.095 \\
\hline
\end{tabular}
The apogee longitudes and times across the top of the graph are naturally ordered oppositely to the magnitudes of the circularization burns. The thrust termination points are indicated as small circles on the magnified inset graph. The solid rocket reaches full speed very early, so it climbs steeply through the atmosphere to avoid excessive drag.

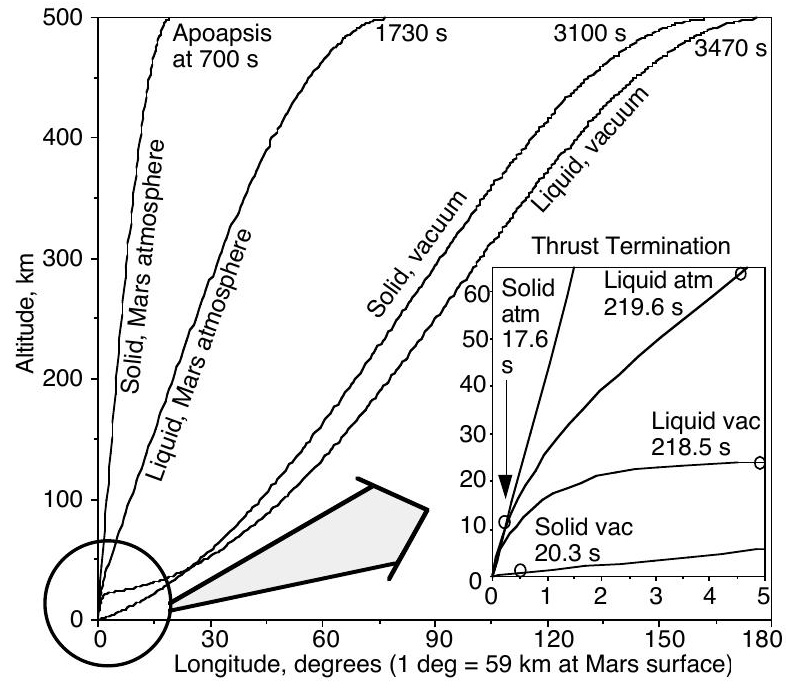

Figure 4. Baseline MAV trajectory profiles.

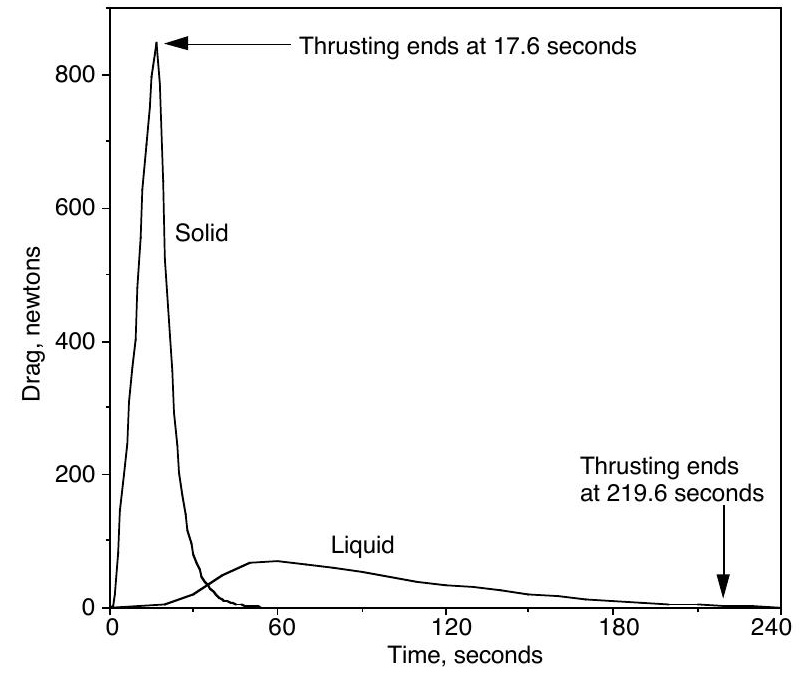

Figure 5. Mars atmospheric drag. 
The vertical thrust component at the moment of launch must be at least high enough to lift the vehicle's weight. This rule determines optimum launch angles for both vacuum cases. Figure 4 shows that the liquid trajectory in vacuum starts close to vertical but is essentially horizontal at burnout. Thereafter, this particular ascent trajectory amounts to a $24 \mathrm{~km} \times 500 \mathrm{~km}$ orbit. The $24 \mathrm{~km}$ periapsis altitude is consistent with a circularization $\Delta \mathrm{v}$ (Table 4) less than for Path A (Table 2).

Drag during the baseline atmospheric trajectories is plotted in Figure 5. The solid-propelled MAV experiences increasing drag, up until Stage 1 thrust termination. The curve then plummets as the vehicle slows and exits the atmosphere. The liquid propelled MAV spends more time in the atmosphere, at lower speeds. Its drag curve decays to a negligible level by the time of thrust termination. The drag peaks for these very different optimized trajectories are a similar fraction of each one's own thrust level, $8.5 \%$ and $7 \%$ for solid and liquid respectively.

Extra propellant consumption is related to the integral of drag, not the magnitude. The areas under the solid and liquid curves are $11,850 \mathrm{~N}-\mathrm{s}$ and $6580 \mathrm{~N}-\mathrm{s}$, respectively. Dividing by specific impulses indicates that $4.3 \mathrm{~kg}$ of solid propellant, or $2.2 \mathrm{~kg}$ of liquid propellants, would be consumed to overcome drag.

A more complete comparison can be cast in terms of propellant quantities, by simply using the rocket equation with the numbers listed in Table 4. Neglecting staging, propellant masses of $79.7 \mathrm{~kg}$ (solid) and $74.5 \mathrm{~kg}$ (liquid) were calculated from the $\Delta v$ totals and specific impulses. Much of the difference is due to specific impulse, i.e. reaching the liquid $\Delta \mathrm{v}$ at the Isp of the solid rocket requires $78.0 \mathrm{~kg}$ of propellant. The differences in drag, gravity losses, and trajectory efficiency account for the rest.

Considering the above descriptions of the four paths to orbit, and the drag calculations, it could be said that the liquid thrust level offers the better compromise between gravity losses and drag losses. Nothing so far is conclusive for propulsion choices, since there are other factors to take into account. For example, a solid-propelled MAV needs at least 2 stages, but a liquid MAV might have only 1 stage.

\section{MAV Design and Propulsion Questions}

Propulsion choices affect trajectory optimization, which in turn drives propulsion requirements. Therefore, further analysis based on the trajectory results can help to answer some more specific propulsion questions, such as

Table 5. Propulsion trade questions for Mars ascent.

\begin{tabular}{|l|l|}
\hline 1 & Solid or liquid? \\
\hline 2 & How many stages, and how should $\Delta v$ be split among them? \\
\hline 3 & Tall narrow MAV with tilt-up launcher, or short wide MAV? \\
\hline 4 & What is the optimum launch thrust to minimize delivered $\Delta v ?$ \\
\hline 5 & $\begin{array}{l}\text { Does it help to reduce solid thrust for trajectory efficiency, } \\
\text { considering that Isp may have to be sacrificed for slower burning? }\end{array}$ \\
\hline 6 & $\begin{array}{l}\text { Does less liquid thrust reduce engine mass by a greater amount } \\
\text { than the extra propellant required by an off-optimum trajectory? }\end{array}$ \\
\hline 7 & $\begin{array}{l}\text { What is the trade for a liquid restart to circularize, compared to a } \\
\text { low-thrust sustainer burn that keeps the tanks settled? }\end{array}$ \\
\hline 8 & Can a 100-kg solid propelled MAV be built? \\
\hline 9 & Can a 100-kg liquid propelled MAV be built? \\
\hline
\end{tabular}
those listed in Table 5.

The baseline simulation results have already shed light on some of these questions. The rest of this paper will address the issues in more detail, separately for solid and liquid propulsion. Additional trajectory calculations will be presented for special cases that depart from the baseline vehicle design parameters.

\section{Solid Staging Analysis}

Table 4 indicates that a solid-propelled MAV would have two stages, with almost $2 / 3$ of the $\Delta v$ on Stage 1, to obtain the least total $\Delta \mathrm{v}$ to orbit. However, a different $\Delta \mathrm{v}$ split may improve the net combination of trajectory performance and vehicle performance, even though total $\Delta \mathrm{v}$ would be greater. Figure 6 shows how total $\Delta \mathrm{v}$ increases as the share for each stage departs

from the design point of Table 4. As described before, the total $\Delta v$ was determined at each selected Stage 1 propellant load (x-axis). The staging question can now be formulated as follows. Given attainable propellant mass fractions for solid rocket stages, which point in Figure 6 maximizes the payload?

If the stages are $100 \%$ propellant with mass-less hardware, then the stage split doesn't matter for MAV optimization, so the least total $\Delta \mathrm{v}$ trajectory remains the best. A spreadsheet was prepared to build a more complete picture from Figure 6 data and the rocket equation. Figure 7 is the resulting contour plot of payload and the Figure 6 abscissa, with stage propellant fractions chosen as the independent variables. 


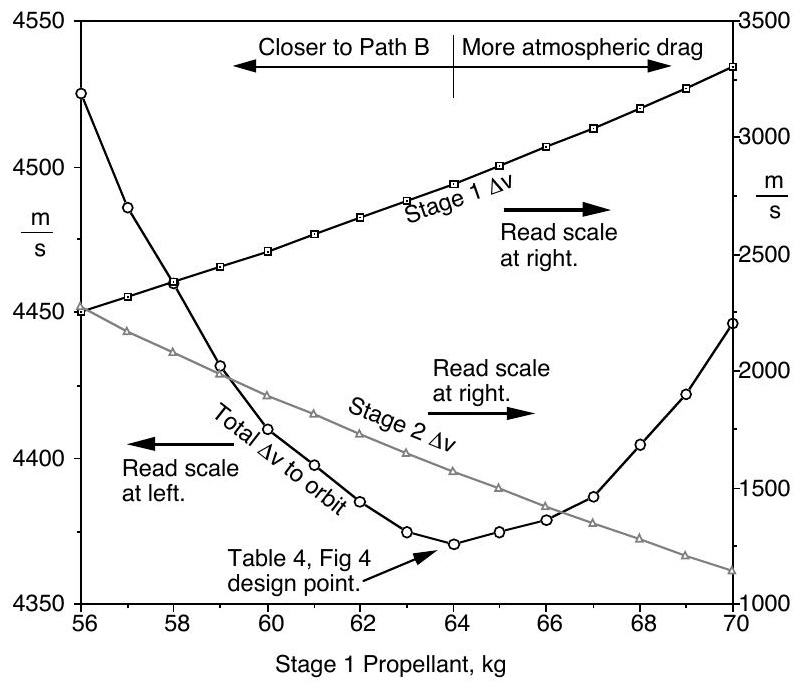

Figure 6. Velocity variation with solid stage share.

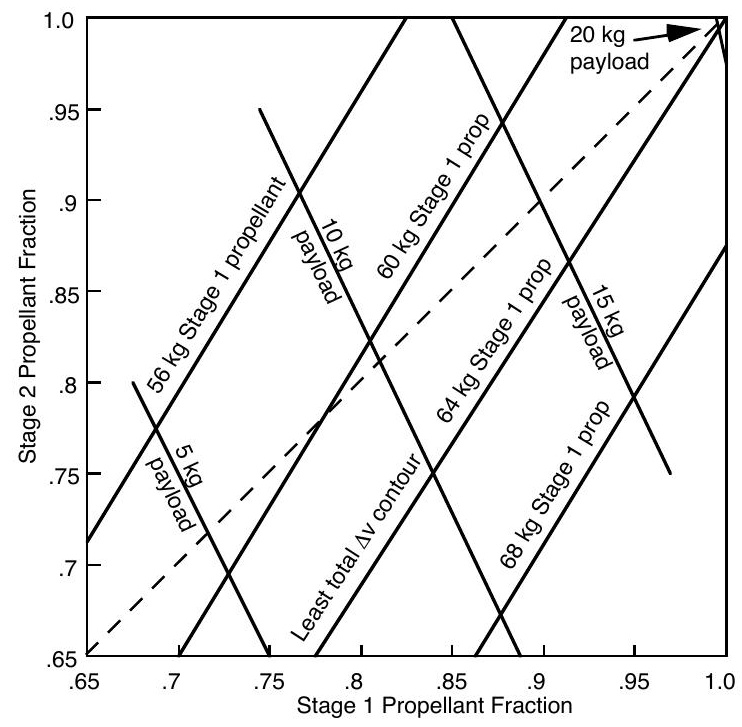

Figure 7. Effect of solid stage propellant fractions.

Much can be appreciated from a careful study of Figure 7. Any point along the 64-kg contour represents use of the least total $\Delta v$ trajectory (note 64-kg point in Fig 6). This contour intersects the upper right corner of the graph, at the point of maximum payload and mass-less stage hardware, for the reason noted just above. However, the maximum payload point attainable in reality may not be along the 64-kg contour, depending on stage propellant fractions that can actually be achieved.

As would be expected, a trend across Figure 7 is that better Stage 1 technology ( $+x$ direction) increases the desired Stage 1 propellant load. Conversely, improving Stage 2 technology (+y direction) reduces the Stage 1 propellant load. The diagonal dashed line represents equal propellant fractions for the two stages. Moving to heavier hardware along the dashed line reduces the size of Stage 1, i.e. the desired design point shifts to the left in Figure 6. This happens because the overall design can suffer from Stage 1 inert mass, if the first stage carries more than its best share of the total $\Delta \mathrm{v}$. At the lower left corner of Figure 7, the dashed line approaches the 56-kg contour, near the point of equally-shared $\Delta \mathrm{v}$ per Figure 6.

Figure 7 provides a useful overview of the 2-stage solid-propelled MAV design trade, in which the physical realities of Mars ascent trajectories are implicit. The remaining unknown is, what propellant fractions are possible for complete solid rocket stages (not just motors) which mass roughly $70-80 \mathrm{~kg}$ total for Stage 1 , and about $15 \mathrm{~kg}$ for Stage 2. In general, larger stages can have better propellant fractions than smaller ones, due to the difficulties of miniaturization. An example of such a point is $84 \%$ propellant in Stage 1 , at $75 \%$ for Stage 2 , which would permit a $10 \mathrm{~kg}$ payload per Figure 7. The initial and burnout masses of Stage 2 are $13.8 \mathrm{~kg}$ and $3.45 \mathrm{~kg}$, which indicates the extent of miniaturization needed. This design point is on the $64-\mathrm{kg}$ contour, so that it happens to use the best trajectory.

It is likely that Stage 1 needs more guidance and control hardware for atmospheric flight, and perhaps Stage 2 could be little more than a bare solid rocket motor if spin stabilization is used. This suggests consideration of the region above and to the left of the dashed line. However, even if Stage 2 could have a very high propellant fraction at its small size (e.g. just $1 \mathrm{~kg}$ of hardware for a 10-kg propellant grain), the steep slope of the payload contours in Figure 7 does not permit a particularly poor propellant fraction for Stage 1. This slope partly reflects the trajectory optimization bias toward more $\Delta \mathrm{v}$ on Stage 1.

The steep payload contour slope means that the feasibility of a 2-stage solid-propelled MAV depends heavily on what propellant fraction can be achieved for Stage 1. If it is only $75 \%$, for example, Figure 7 shows that it would be essentially impossible to deliver a 10-kg payload. The latter includes not just the Mars geology samples, but also their packaging and everything else needed, other than rocket stages.

The above interpretation may seem contrary to conventional wisdom for launch vehicles. In particular, payload capacity is known to be more sensitive to upper stage weight growth than to lower stage weight growth. This is perfectly true on earth, where extra weight on a first stage is not in itself a problem. There is no contradiction, for two reasons. First, comparing propellant fractions is not the same thing as considering changes in stage absolute mass. Second, the total launch mass on Mars is limited. In terms of the conventional wisdom, Stage 1 of the MAV is in reality an upper stage above many others in the MSR mission stack. 
Consider what would happen if trajectory optimization and staging optimization could be entirely independent of one other. The total $\Delta \mathrm{v}$ curve in Figure 6 would be a horizontal line at the least $\Delta \mathrm{v}$. Maximizing the payload then depends only on vehicle design, i.e. stage inert masses. There would be no "least total $\Delta \mathrm{v}$ contour" in a graph like Figure 7. There would be no advantage to unequal $\Delta \mathrm{v}$ sharing between stages having equal propellant fractions. Separation of vehicle design from trajectory design does happen for liquid propulsion, because the staging point can be chosen independently from the two $\Delta \mathrm{v}$ events.

\section{Liquid Staging Analysis}

The liquid $\Delta \mathrm{v}$ split shown in Table 4 is too unequal to efficiently use a separate stage just for circularization (6\% of the total $\Delta \mathrm{v}$ ). Whether the ascent is accomplished with two stages or just one, an engine restart is needed to circularize the orbit at $500 \mathrm{~km}$ above Mars. Therefore, staging considerations are essentially independent of the trajectory, for liquids. The requirement is simply to deliver the total amount of $\Delta \mathrm{v}$ necessary to follow the chosen trajectory. As noted already, there is no liquid version of Figure 6 to constrain the staging trade.

Figure 8 was generated from straightforward spreadsheet calculations, which incorporated the rocket equation and the total $\Delta \mathrm{v}$ requirement of $4157 \mathrm{~m} / \mathrm{s}$. For each chosen pair of propellant fractions for the two stages $(\mathrm{x}, \mathrm{y})$, the size of the first stage (parameterized as propellant mass) was varied to maximize the payload. The resulting mass values were initially labeled on the field, then replaced with two sets of contours to facilitate visual interpretation.

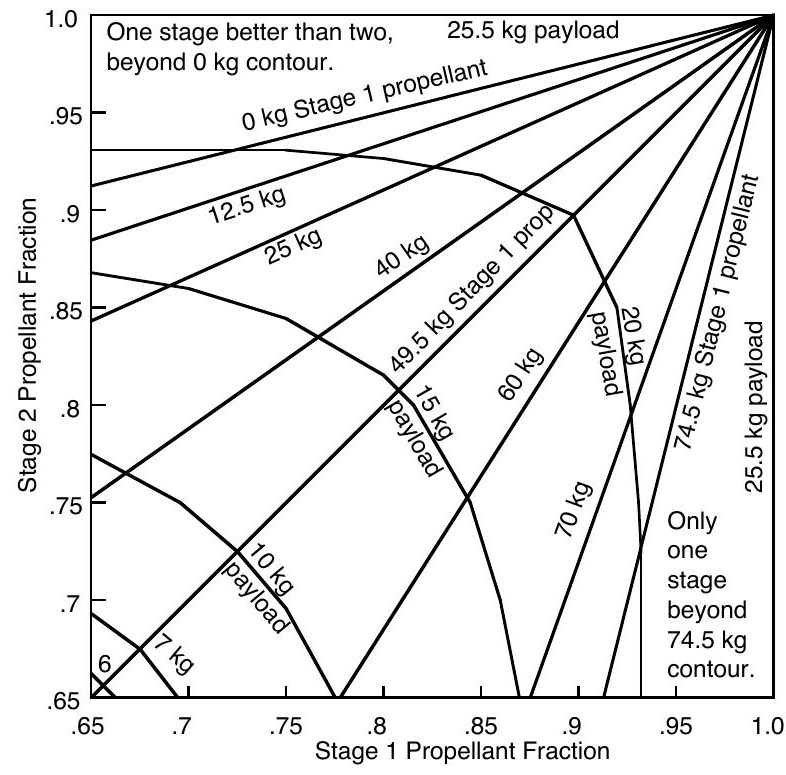

Figure 8. Effect of liquid stage propellant fractions.

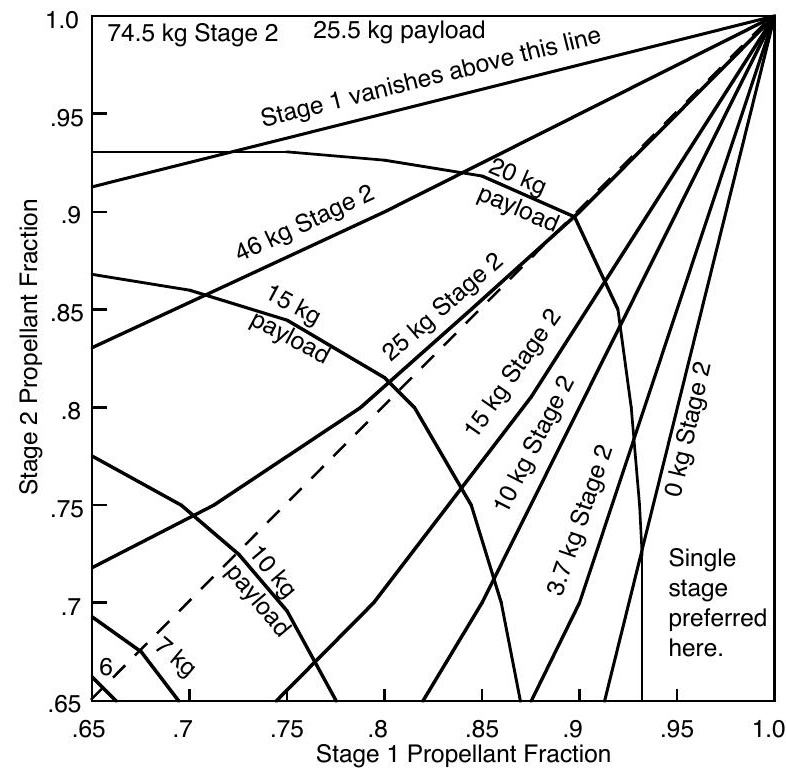

Figure 9. Stage 2 mass contours on Figure 8 graph.

Figure 8 has a very different appearance from Figure 7, because every point on the liquid graph represents the same $\Delta \mathrm{v}$. The propellant contours all converge at the mass-less hardware point, for a simple reason. In the absence of rocket hardware realities in the upper right corner of the graph, the liquid trade has nothing left to bias the $\Delta \mathrm{v}$ split. Comparing the payload contours between the solid and liquid graphs indicates that a $15 \mathrm{~kg}$ payload capability, for example, may be easier to obtain using liquid, depending on propulsion hardware realities. A 100-kg liquid MAV might even lift $20 \mathrm{~kg}$, which is not possible for a solid within the same mission mass budget.

The liquid trade shows that two stages should share the $\Delta \mathrm{v}$ equally to maximize payload, but only if they can be built to have the same propellant mass fractions. In particular, the propellant contour angled at 45 degrees represents the mass that Stage 1 must burn (at Isp=310 s) to obtain half of the $\Delta \mathrm{v}$. The graph is symmetrical about the diagonal, except for the propellant masses. As was the case for the solid stage trade, a higher propellant fraction for Stage 1 tends to increase its mass and $\Delta \mathrm{v}$ share. An actual MAV design point would most likely not be on the diagonal. If Stage 1 is $80 \%$ liquid and Stage 2 is at $70 \%$, Figure 8 shows that the payload would be about $12 \mathrm{~kg}$.

There is a triangular region along the right side of Figure 8 , beyond the $74.5 \mathrm{~kg}$ propellant contour. The Stage 1 propellant load does not rise further within the triangle, because $74.5 \mathrm{~kg}$ is sufficient to reach orbit. The second stage actually vanishes within that region of the graph, i.e. a single-stage MAV delivers the most payload therein. 
The payload trades directly with stage hardware, so payload mass contours inside the triangle are exactly vertical. The 25.5-kg payload contour (100-74.5) is along the right border of the graph, where Stage 1 inert mass equals zero.

This maximum single-stage payload contour also extends along the top of the graph. There is another symmetrical triangular single-stage region above the $0 \mathrm{~kg}$ Stage 1 propellant contour, because the math alone does not rule it out. If Stage 2 has a very high propellant fraction and that of Stage 1 is rather poor, then Stage 1 vanishes and Stage 2 stands alone.

The practical size of the single-stage region is larger than Figure 8 indicates, because the second stage becomes exceedingly small before the mathematical border is reached. Figure 9 was plotted using the same spreadsheet calculations, to show how small Stage 2 must be for a given optimized design point. The $80 \%, 70 \%$ point considered previously has a $15-\mathrm{kg}$ upper stage. Thirty percent of that, or $4.5 \mathrm{~kg}$, would be budgeted for actually building the upper stage hardware. The latter includes propulsion, guidance, and control.

Closer to the single-stage region, the point at $90 \%$ for Stage 1 and $70 \%$ for Stage 2 has a $3.7-\mathrm{kg}$ upper stage per Figure 9. It would have $2.6 \mathrm{~kg}$ of liquids and only a $1.1-\mathrm{kg}$ empty mass. A larger $10-\mathrm{kg}$ upper stage atop a $90 \%$ first stage would need to be $80 \%$ propellant, which still allows only $2 \mathrm{~kg}$ for hardware. However, there is always the option to sacrifice payload in a direct exchange for more upper stage inert mass. At the $90 \%, 80 \%$ point, the payload is $18 \mathrm{~kg}$. Reducing it to $16 \mathrm{~kg}$ would double the $2-\mathrm{kg}$ stage hardware budget. This additional trade, to avoid difficulties in implementing tiny upper stages, may be considered at any point represented by Figures 8 and 9 .

Table 6. Mass breakdown of a single-stage liquid MAV.

\begin{tabular}{|l|l|l|l|l|}
\hline $\begin{array}{l}\text { Propellant } \\
\text { mass, kg }\end{array}$ & $\begin{array}{l}\text { Stage liquid } \\
\text { fraction, \% }\end{array}$ & $\begin{array}{l}\text { Stage } \\
\text { mass, kg }\end{array}$ & $\begin{array}{l}\text { Stage inert, } \\
\mathrm{kg}\end{array}$ & $\begin{array}{l}\text { Payload } \\
\text { mass, kg }\end{array}$ \\
\hline \hline 74.5 & 74.5 & 100 & 25.5 & 0.0 \\
\hline 74.5 & 80 & 93.2 & 18.6 & 6.8 \\
\hline 74.5 & 83 & 89.8 & 15.3 & 10.2 \\
\hline 74.5 & 85 & 87.7 & 13.2 & 12.3 \\
\hline 74.5 & 88 & 84.7 & 10.2 & 15.3 \\
\hline 74.5 & 90 & 82.8 & 8.3 & 17.2 \\
\hline 74.5 & 95 & 78.5 & 3.9 & 21.5 \\
\hline 74.5 & 100 & 74.5 & 0 & 25.5 \\
\hline
\end{tabular}

Table 7. Stack of two identical liquid stages.

\begin{tabular}{|l|l|l|l|l|}
\hline $\begin{array}{l}\text { Propellant } \\
\text { mass, kg }\end{array}$ & $\begin{array}{l}\text { Stage liquid } \\
\text { fraction, \% }\end{array}$ & $\begin{array}{l}\text { Stage } \\
\text { mass, kg }\end{array}$ & $\begin{array}{l}\text { Stage inert, } \\
\mathrm{kg}\end{array}$ & $\begin{array}{l}\text { Payload } \\
\text { mass, kg }\end{array}$ \\
\hline \hline 31.47 & 63 & 49.95 & 18.5 & 0.1 \\
\hline 31.90 & 65 & 49.1 & 17.2 & 1.9 \\
\hline 32.90 & 70 & 47.0 & 14.1 & 6.0 \\
\hline 33.81 & 75 & 45.1 & 11.3 & 9.9 \\
\hline 34.63 & 80 & 43.3 & 8.7 & 13.4 \\
\hline 35.38 & 85 & 41.6 & 6.2 & 16.7 \\
\hline 36.07 & 90 & 40.1 & 4.0 & 19.8 \\
\hline 36.70 & 95 & 38.6 & 1.9 & 22.7 \\
\hline 37.27 & 100 & 37.3 & 0 & 25.5 \\
\hline
\end{tabular}

be compared directly with that of a single stage in Table 6 . For equal stage propellant fractions, there is just a slight improvement at the high end above $90 \%$. At $85 \%$ and lower, the notion of two stacked stages appears to have a lot to offer. However, it is not easy to achieve the same propellant fraction at half scale. Unlike the situation for a small upper stage, a smaller first stage would still have to deliver enough thrust for launch and efficient ascent. Even the optimized 2-stage liquid MAV designs cannot have a Stage 1 propellant fraction as high as a single stage MAV, for the same reason, i.e. the Stage 1 engine mass is essentially fixed. There is also the mass of separation hardware to contend with for any multi-stage option.

Relative to solids, a specific comparison can be made with reference to Figure 7 and Table 6. A 100-kg solid rocket MAV can launch a payload just over $12 \mathrm{~kg}$ if both stages are $85 \%$ (or $90 \%$ and $75 \%$ in combination). The upper stage burnout mass is just $2.3 \mathrm{~kg}$ (or $3.3 \mathrm{~kg}$ ). At the same $85 \%$ minimum propellant fraction, a single $88-\mathrm{kg}$ liquid stage offers the same $12 \mathrm{~kg}$ payload, without the need to miniaturize technology further for an upper stage. 


\section{Mars Ascent Vehicle Shape}

Returning now to Table 5, the third question is motivated by the constraints of Earth-to-Mars transportation. Aeroshells for decelerating upon arrival in Mars' atmosphere are shaped as in Figure 10. A long, narrow MAV would most likely land on Mars in a horizontal orientation. It would need a tilt-up mechanism for a vertical launch, or a way to set the azimuth for a non-vertical launch. The ideal MAV would perhaps avoid both, by fitting on a Mars lander while oriented for a vertical launch.

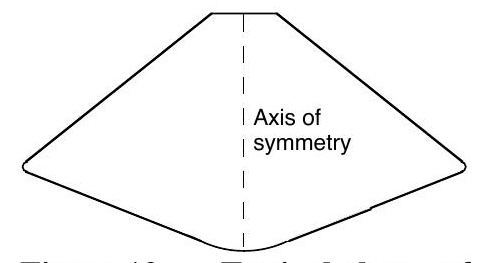

Figure 10. Typical shape of aeroshell for Mars arrival.

Considerations of packaging, structural load paths, and balancing all lead to a relatively tall, narrow stack for a 2 -stage solid rocket. Even if a short, stout solid-propelled MAV could be built, its atmospheric drag would be prohibitively high. The delivered $\Delta \mathrm{v}$ requirement would increase to overcome higher drag, while following a less efficient steeper trajectory closer to Path B.

The answer is not quite as clear for the shape of a liquid-propelled MAV. Stage designs having side-by-side tanks have been proposed in the past, e.g. 4 tanks to balance unequal masses of 2 liquids. Mars ascent simulations were run with a higher, 0.5 square meter frontal area. Everything else was kept the same as in the baseline liquid ascent case. The trajectory results are compared in Table 8. As would be expected, the trajectory was slightly closer to Path B than the baseline liquid trajectory indicated in Table 4 and in Figure 4.

Table 8. Importance of liquid MAV frontal area.

\begin{tabular}{|l|l|l|}
\hline & Table 4 Liquid MAV & High drag liquid MAV \\
\hline \hline Frontal area & $0.2 \mathrm{~m}^{2}$ & $0.5 \mathrm{~m}^{2}$ \\
\hline Total $\Delta \mathrm{v}$ to orbit & $4157 \mathrm{~m} / \mathrm{s}$ & $4283 \mathrm{~m} / \mathrm{s}$ \\
\hline Launch $\Delta \mathrm{v}$ & $3900 \mathrm{~m} / \mathrm{s}$ & $3889 \mathrm{~m} / \mathrm{s}$ \\
\hline$\Delta \mathrm{v}$ to circularize & $257 \mathrm{~m} / \mathrm{s}$ & $394 \mathrm{~m} / \mathrm{s}$ \\
\hline Apoapsis longitude & $78.9 \mathrm{deg}$ & $59.4 \mathrm{deg}$ \\
\hline Peak drag & $69 \mathrm{~N}$ & $148 \mathrm{~N}$ \\
\hline Integrated drag & $6580 \mathrm{~N}-\mathrm{s}$ & $12,150 \mathrm{~N}-\mathrm{s}$ \\
\hline Launch propellant & $72.3 \mathrm{~kg}$ & $72.2 \mathrm{~kg}$ \\
\hline $\begin{array}{l}\text { Total propellant } \\
\text { (single stage equiv.) }\end{array}$ & $74.5 \mathrm{~kg}$ & $75.6 \mathrm{~kg}$ \\
\hline
\end{tabular}

not changed, only the frontal area. A short MAV would most likely have a higher drag coefficient, even with aerodynamic shrouding heavier than the nosecone of a tall MAV. In addition to quantifying these changes individually, their net effect would have to be considered in view of design information for a tilt-up launch mechanism. What is certain, is that Mars ascent drag is significant enough to strongly influence design decisions for any 100-kg MAV, regardless of the propellant choice.

\section{Solid Thrust Reduction}

The fourth through sixth questions in Table 5 ask what can be gained by optimizing thrust, to reach the best compromise between drag losses and gravity losses. The best launch thrust at Isp $=280 \mathrm{~s}$ was found to be in the range $1000-2000 \mathrm{~N}$. It is not a sharp optimum.

Typically for solid propulsion applications, the propellant quantity and thrust are not independently selected. Burn rates are determined by propellant formulation, exposed area, and chamber pressure. Propellant additives which slow the reaction may affect specific impulse. Attempts to reduce the exposed area may impose packaging and structural constraints. Pressure changes affect the burn rate only weakly. A larger nozzle would be required, e.g. for half thrust at one-fifth pressure. ${ }^{14}$ Assuming that existing solid motors are optimized for overall performance, large thrust reductions are not practical. At best, it may be worth considering that a combination of changes could possibly halve the thrust, by reducing propellant fraction, Isp, or both. The relevant question then is whether improved trajectory performance could more than compensate for reduced rocket vehicle performance.

In order to explore the reduced-thrust option, a set of ascent simulations was performed at $5000 \mathrm{~N}$, half the nominal thrust. All other aspects of the conceptual solid-propelled MAV remained the same as in the baseline case. Table 9 shows that the delivered $\Delta \mathrm{v}$ falls by about $100 \mathrm{~m} / \mathrm{s}$. The optimized half-thrust trajectory has a much lower drag peak, prior to motor burnout. The minor change in integrated drag indicates greater duration, which results from lower altitudes initially, closer to Path A. The apogee conditions are consistent with the path change, i.e. the 
Table 9. Effect of halving solid MAV thrust.

\begin{tabular}{|l|l|l|}
\hline & Table 4 Solid MAV & Half thrust solid MAV \\
\hline \hline Launch thrust & $10,000 \mathrm{~N}$ & $5,000 \mathrm{~N}$ \\
\hline Total $\Delta \mathrm{v}$ to orbit & $4371 \mathrm{~m} / \mathrm{s}$ & $4272 \mathrm{~m} / \mathrm{s}$ \\
\hline Launch $\Delta \mathrm{v}$ & $2803 \mathrm{~m} / \mathrm{s}$ & $2985 \mathrm{~m} / \mathrm{s}$ \\
\hline$\Delta \mathrm{v}$ to circularize & $1567 \mathrm{~m} / \mathrm{s}$ & $1287 \mathrm{~m} / \mathrm{s}$ \\
\hline Apoapsis longitude & $19.6 \mathrm{deg}$ & $24.3 \mathrm{deg}$ \\
\hline Peak drag & $852 \mathrm{~N}$ & $394 \mathrm{~N}$ \\
\hline Integrated drag & $11,850 \mathrm{~N}-\mathrm{s}$ & $10,940 \mathrm{~N}-\mathrm{s}$ \\
\hline Launch propellant & $64.0 \mathrm{~kg}$ & $66.3 \mathrm{~kg}$ \\
\hline $\begin{array}{l}\text { Total propellant } \\
\text { (single stage equiv.) }\end{array}$ & $79.7 \mathrm{~kg}$ & $78.9 \mathrm{~kg}$ \\
\hline
\end{tabular}

greater longitude and reduced $\Delta \mathrm{v}$ to circularize. A possible drawback is that the $\Delta \mathrm{v}$ split is further from even, compared to the baseline.

The ratio of the $\Delta v$ totals in Table 9 is consistent with a reduction in Isp from $280 \mathrm{~s}$ to $274 \mathrm{~s}$. Thus if the burn rate could be halved by using a propellant formulation that sacrificed less than $6 \mathrm{~s}$ of specific impulse, it may be worth looking into. Alternatively, the last row in Table 9 shows that almost an extra kilogram of stage hardware would be allowable for design changes that can reduce thrust by $50 \%$. Obtaining the exact numbers requires a staging analysis, since reducing thrust is only of interest for Stage 1 .

\section{Liquid Thrust Optimization}

Liquid propulsion is free from underlying constraints on thrust level. To avoid excess engine mass and to improve packaging, extra thrust is usually avoided. Mars launch simulations were repeated to find the minimum required $\Delta \mathrm{v}$ as a function of thrust. At each selected thrust, multiple trajectories were tested as described previously in this paper. The results are presented in Figure 11. The gravity loss increases steeply at the left side of the graph, because thrust equals Mars liftoff weight at $375 \mathrm{~N}$.

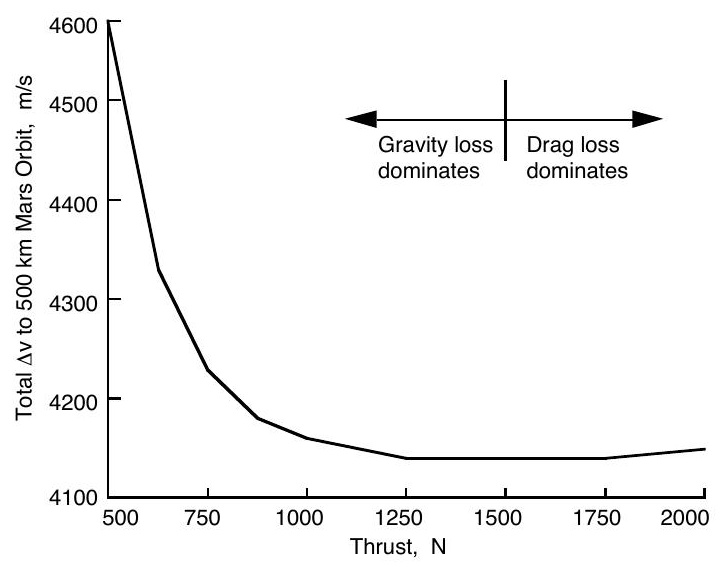

Table 10. Net effect of engine mass.

\begin{tabular}{|l|l|l|l|l|}
\hline Thrust, $\mathrm{N}$ & $\Delta \mathrm{v}$ Needed & Burnout $\mathrm{kg}$ & $\Delta \mathrm{v}$ Avail. & $\Delta$ v Excess \\
\hline \hline 500 & $4602 \mathrm{~m} / \mathrm{s}$ & 24.453 & $4279 \mathrm{~m} / \mathrm{s}$ & $-323 \mathrm{~m} / \mathrm{s}$ \\
\hline 625 & 4326 & 24.703 & 4248 & -78 \\
\hline 750 & 4225 & 24.953 & 4217 & -8 \\
\hline 875 & 4178 & 25.203 & 4187 & +9 \\
\hline 1000 & 4157 & 25.453 & 4157 & 0 \\
\hline 1250 & 4140 & 25.953 & 4098 & -42 \\
\hline 1500 & 4141 & 26.453 & 4040 & -101 \\
\hline 2000 & 4152 & 27.453 & 3927 & -255 \\
\hline
\end{tabular}

Figure 11. Effect of thrust at Isp=310 s.

If engine mass didn't matter, the optimum thrust would be in the range 1250-1500 N. In reality, a better choice for thrust is further to the left. There is no mission advantage to increasing thrust toward $2000 \mathrm{~N}$, because both $\Delta \mathrm{v}$ and engine mass would increase. In this context, the practical definition of engine mass is, all stage hardware which can be made lighter if thrust is reduced. The derivative of mass with respect to thrust can be used, in combination with Figure 11, to find the optimum design point.

The earth weight of large launch vehicle engines is about $1 \%$ of thrust. Engines aren't that good near $1000 \mathrm{~N}$. Table 10 was generated using the assumption that engine weight (on earth) is about $2 \%$ of thrust. More precisely, the derivative of inert mass with respect to thrust is $.002 \mathrm{~kg} / \mathrm{N}$. Required $\Delta \mathrm{v}$ is from Figure 11. Available $\Delta \mathrm{v}$ varies from the baseline under the assumption that hardware mass trades directly with propellant, and everything else stays the same. The point of departure uses the previous data for a single-stage 100-kg MAV at $1000 \mathrm{~N}$ thrust.

By choice, the excess $\Delta v$ is zero for the baseline case at $1000 \mathrm{~N}$. The last column in Table 10 shows that a small reduction in thrust, to $875 \mathrm{~N}$, improves the baseline case. There would be a greater incentive to reduce thrust if heavier engine technology is used, but the curve in Figure 11 quickly becomes a wall below $750 \mathrm{~N}$.

A practical point worth noting is that custom lightweight hardware is needed. Thrust and mass are not easily varied after hardware is designed, even though the derivative used above exists. The mass of a liquid MAV might grow, over the course of its development program. For this reason, it may be better to err toward higher thrust than 
to plan for the optimum. When the thrust trade results are viewed in this light, the 1000-N thrust level appears to be a good starting point for a $100-\mathrm{kg}$ MAV design.

Another question raised in Table 5 for liquid propulsion is whether it makes sense to consider a sustainer burn to keep the tanks settled. In the baseline trajectory of Figure 4, the optimized ascent burn ends at $220 \mathrm{~s}$, and the apoapsis is reached at $1730 \mathrm{~s}$ after launch. A 1-N thrust level for example can be sufficient for settling. Over the $1510 \mathrm{~s}$ time period, propellant consumption would be $0.5 \mathrm{~kg}$ at Isp=310 s, and at most $1 \mathrm{~kg}$ if the settling thrusters have a much lower specific impulse. Less $\Delta \mathrm{v}$ would be needed to circularize. If the hardware mass for microgravity propellant acquisition approaches $1 \mathrm{~kg}$, then it would make sense to consider a continuous settling burn.

\section{Three Stage Solid MAV}

Considering that the trajectory results do not favor a solid-propelled MAV, it is worth asking what else can be done to reduce drag. A concept based on References 5 and 6 seeks to minimize drag, by using a 3-stage trajectory. First, there is a vertical launch to a point just above most of the atmosphere. This is followed by 2 more burns, which can essentially use Path A because there is very little drag beyond that point. The vertical launch reduces drag in 2 ways. It uses the shortest path through the atmosphere. Also, average speed through the atmosphere is reduced because the vehicle coasts to altitude after a minimum burn.

If the initial altitude reached by Stage 1 is too high, the trajectory will be inefficient like Path B. Analytical calculations done with a spreadsheet show that above $54 \mathrm{~km}$, the ideal 3 -stage $\Delta \mathrm{v}$ exceeds $4371 \mathrm{~m} / \mathrm{s}$, i.e. even in vacuum it cannot improve upon the optimized 2-stage case in Table 4 . If the initial altitude goal is too low, then the first stage becomes moot and the 3-stage MAV merely follows the optimized 2-stage trajectory.

The FORTRAN code was modified to simulate the 3-stage ascent. Results indicate that the least total $\Delta \mathrm{v}$ occurs when the first stage lofts the vehicle to $25 \mathrm{~km}$ above Mars. The maximum drag is only $15 \%$ of the Figure 5 peak. However, the advantage over the 2-stage case is a slight $12 \mathrm{~m} / \mathrm{s}$, at $4359 \mathrm{~m} / \mathrm{s}$ total to orbit. It is not a sharp optimum, as results are all in the range $4371 \pm 20 \mathrm{~m} / \mathrm{s}$ for altitudes between zero and $40 \mathrm{~km}$.

In general, there is the potential for a 3 -stage vehicle to lift a greater payload than 2 stages. However, the $\Delta \mathrm{v}$ split required by the specialized 3-stage trajectory is far from ideal. The middle stage must deliver more velocity than the main stage of the 2-stage solid MAV. Only about $500 \mathrm{~m} / \mathrm{s}$ is needed from each of the other 2 stages, depending on initial altitude. Considering the small apoapsis burn, the first 2 stages constitute a MAV that has an "upside down" $\Delta \mathrm{v}$ split. The bottom line is that the 3-stage MAV offers virtually no $\Delta \mathrm{v}$ reduction, and the stage miniaturization problem becomes more difficult.

\section{Conclusion}

The most significant result from the trajectory simulations and staging calculations is that a liquid propelled MAV offers more payload mass than solid rocket MAV options, if stage propellant fractions are the same for both technologies. In addition to specific impulse, key reasons are that a solid propelled vehicle experiences higher aerodynamic drag, and that solid staging cannot be optimized independently from the trajectory.

Additional realism in the trajectory simulations would be unlikely to change the preference for liquid propulsion. In particular, the velocity of planet rotation $(240 \mathrm{~m} / \mathrm{s}$ at the equator, neglected herein) is aligned with Path A. Planet rotation thus favors trajectories closer to Path A than to Path B. Active steering would also be unlikely to improve the solid trajectory more than the liquid one, because guidance for solids is closer to a "point and shoot" proposition.

The lack of available rocket hardware is a separate issue from the above points. For either solid or liquid, the necessary stage propellant mass fractions are beyond the state of the art at the desired size scale. Thus the viability of any MAV design, sized for MSR mission affordability, hinges on what propellant fractions can be achieved through innovation. A major solid rocket technology challenge is to provide thrust vector control with very little hardware mass. The challenge for liquid rocket technology is to reduce hardware mass significantly below that of conventional pressure-fed satellite propulsion, e.g. by scaling down pump-fed launch vehicle technology.

For either solid or liquid, an upper stage would need extreme miniaturization down to the order of $10 \mathrm{~kg}$, with relatively little tolerance for sacrificing propellant fraction. Technology development efforts toward high propellant fractions may be more likely to succeed on a scale closer to $100 \mathrm{~kg}$ than to $10 \mathrm{~kg}$. A single-stage liquid propelled Mars ascent vehicle appears to offer a viable alternative to difficult miniaturization.

\section{Acknowledgment}

This work was performed under the auspices of the U.S. Department of Energy, by the University of California, Lawrence Livermore National Laboratory under Contract W-7405-Eng-48. 


\section{References}

${ }^{1}$ Space Studies Board, NRC, "New Frontiers in the Solar System: An Integrated Exploration Strategy,” ISBN 0-309-08495-4, The National Academies Press, 2003.

${ }^{2}$ Weaver, W.L., "Mars Surface-to-Orbit Vehicles for Sample Return Missions,” J. Spacecraft, Vol. 11, No. 6, 1974, pp 426427. 385 .

${ }^{3}$ Wercinski, P.F., “Mars Sample Return: A Direct and Minimum-Risk Design,” J. Spacecraft, Vol. 33, No. 3, 1996, pp. 381-

${ }^{4}$ Guernsey, C.S., “Mars Ascent Propulsion System (MAPS) Technology Program: Plans and Progress,” AIAA Paper 983664, July 1998.

${ }^{5}$ O’Neil, W.J, Adler, M., Caldwell, D, et al, "Mars Sample Return Project: Mars Ascent Vehicle Industry Briefing,” NASA Jet Propulsion Laboratory, Pasadena California, April 21999.

${ }^{6}$ Wilcox, B.H., "Miniature Ascent Vehicles Derived from the Navy's Air-Launched Satellite Developed in 1958," AIAA Paper 2001-3879, July 2001.

${ }^{7}$ Stephenson, D., "Mars Ascent Vehicle — Concept Development," AIAA Paper 2002-4318, July 2002.

${ }^{8}$ Whitehead, J.C., "Mars Ascent Propulsion Options for Small Sample Return Vehicles," AIAA Paper 97-2950, July 1997.

${ }^{9}$ Whitehead, J.C. and Guernsey, C.S., "Mars Ascent Propulsion on a Minimum Scale," Acta Astronautica, Vol. 45, Nos. 4-9, 1999, pp 319-327.

${ }^{10}$ Whitehead, J.C. and Brewster, G.T., "High Pressure Pumped Hydrazine for Mars Sample Return," J. Spacecraft, Vol. 37 , No. 4, 2000, pp 532-538.

${ }^{11}$ Desai, P.N., Braun, R.D., Engelund, W.D., Cheatwood, F.M., and Kangas, J.A., "Mars Ascent Vehicle Flight Analysis," AIAA Paper 98-2850, June 1998.

${ }^{12}$ Helgostam, L.F., "Requirements for Efficient Mars Launch Trajectories,” J. Spacecraft, Vol. 1, No. 5, 1964, pp 539-544.

${ }^{13}$ Seiff, A. and Kirk, D., "Structure of the Atmosphere of Mars in Summer at Mid-Latitudes," J. Geophys. Res., Vol. 82, No. 28, 1977, pp 4364-4378.

${ }^{14}$ Sutton, G.P, Rocket Propulsion Elements, an Introduction to the Engineering of Rockets, $6^{\text {th }}$ ed., John Wiley \& Sons, Inc., New York, 1992, pp 374-375. 


\section{References}

${ }^{1}$ Space Studies Board, NRC, "New Frontiers in the Solar System: An Integrated Exploration Strategy,” ISBN 0-309-08495-4, The National Academies Press, 2003.

${ }^{2}$ Weaver, W.L., "Mars Surface-to-Orbit Vehicles for Sample Return Missions,” J. Spacecraft, Vol. 11, No. 6, 1974, pp 426427. 385 .

${ }^{3}$ Wercinski, P.F., “Mars Sample Return: A Direct and Minimum-Risk Design,” J. Spacecraft, Vol. 33, No. 3, 1996, pp. 381-

${ }^{4}$ Guernsey, C.S., “Mars Ascent Propulsion System (MAPS) Technology Program: Plans and Progress,” AIAA Paper 983664, July 1998.

${ }^{5}$ O’Neil, W.J, Adler, M., Caldwell, D, et al, "Mars Sample Return Project: Mars Ascent Vehicle Industry Briefing,” NASA Jet Propulsion Laboratory, Pasadena California, April 21999.

${ }^{6}$ Wilcox, B.H., "Miniature Ascent Vehicles Derived from the Navy's Air-Launched Satellite Developed in 1958," AIAA Paper 2001-3879, July 2001.

${ }^{7}$ Stephenson, D., "Mars Ascent Vehicle — Concept Development," AIAA Paper 2002-4318, July 2002.

${ }^{8}$ Whitehead, J.C., "Mars Ascent Propulsion Options for Small Sample Return Vehicles," AIAA Paper 97-2950, July 1997.

${ }^{9}$ Whitehead, J.C. and Guernsey, C.S., "Mars Ascent Propulsion on a Minimum Scale," Acta Astronautica, Vol. 45, Nos. 4-9, 1999, pp 319-327.

${ }^{10}$ Whitehead, J.C. and Brewster, G.T., "High Pressure Pumped Hydrazine for Mars Sample Return," J. Spacecraft, Vol. 37 , No. 4, 2000, pp 532-538.

${ }^{11}$ Desai, P.N., Braun, R.D., Engelund, W.D., Cheatwood, F.M., and Kangas, J.A., "Mars Ascent Vehicle Flight Analysis," AIAA Paper 98-2850, June 1998.

${ }^{12}$ Helgostam, L.F., "Requirements for Efficient Mars Launch Trajectories,” J. Spacecraft, Vol. 1, No. 5, 1964, pp 539-544.

${ }^{13}$ Seiff, A. and Kirk, D., "Structure of the Atmosphere of Mars in Summer at Mid-Latitudes," J. Geophys. Res., Vol. 82, No. 28, 1977, pp 4364-4378.

${ }^{14}$ Sutton, G.P, Rocket Propulsion Elements, an Introduction to the Engineering of Rockets, $6^{\text {th }}$ ed., John Wiley \& Sons, Inc., New York, 1992, pp 374-375. 